\title{
The Racing Airplane of the Future
}

\author{
(Reprint of a Study of Probable Future Developments, Originally Published in the Scientific American of Oct. 22, 1910)
}

By J. Bernard Walker

\begin{tabular}{|c|c|}
\hline $\begin{array}{l}\text { STUDY of the trend of } \\
\text { development in airplane } \\
\text { construction renders it pos- } \\
\text { sible to predict with some } \\
\text { degree of certainty the lead- } \\
\text { ing characteristics of the } \\
\text { airplane of the future, and } \\
\text { especially of that type which } \\
\text { will be built purely for rac- } \\
\text { ing purposes. The following } \\
\text { is an attempted study along } \\
\text { these lines. The writer has } \\
\text { no wish to assume the rôle } \\
\text { of prophet, and the accom- } \\
\text { panying drawings and de- } \\
\text { scription are based mainly }\end{array}$ & $\begin{array}{l}\text { HIS article, originally published during the great airplane meet at Belmont Park in 1910, was an } \\
\text { attempt to forecast the lines along which the development of the airplane would proceed. It was } \\
\text { an engineer's loose study of a problem, to which the engineering profession was about to apply itself } \\
\text { with results of which we were to see the culmination on the battlefields of France and in the memorable } \\
\text { flights across the Atlantic. The present-day interest of this article will be found in its fruitful anticipation } \\
\text { of subsequent developments, as seen in the oval, streamlined nascelle and the sheltered position of the pilot; } \\
\text { the substitution of interior metal wing beams for exterior ties and struts; the retraclable chassis; the gyro } \\
\text { control of the ailerons; and the use of alloy metal throughout, with corrugated metal covering for the wings. } \\
\text { After a lapse of eight years, the Germans, in the summer of 1918, produced the Junker all-metal war mono- } \\
\text { plane, with internally braced wings, covered with corrugated metal. At the present time the retractable } \\
\text { chassis, as suggested in 1910, is being made the subject of much experimental effort.-THE EDITOR. }\end{array}$ \\
\hline
\end{tabular}

doomed the biplane as a purely racing type. When Octave Chanute built the first biplane glider, with its light, but very rigid Pratt trussing of vertical wooden struts and diagonal wire ties, he produced an excellent piece of engineering construction, which has proved to be ideally adapted to the early experimental stage which is now drawing to its close ; but for high-speed results, because of the large sults, because of the large amount of head surface pre-
sented, the Pratt truss was sented, the Pratt truss was
doomed to ultimate extincupon a survey of the work which has been done during the present year of phenomenal development by the designer, the constructor, and the airman. The keynote of this development is to be found in the fact that the speed of the airplane in straight-away flight has risen during the past year from fifty-five to seventy-five miles per hour and that the "blue ribbon" of the air (if we may borrow a nautical phrase) has passed from the biplane to the monoplane, the type which, at the present writing, is so far in the lead as to speed, lightness and stability, that it stands in a class by itself.

The racer of the future, then, will be a monoplane; and in narrowing down to this type, man is but treading in the footsteps of Nature, the master builder, who, working through a process of evolution that hos stretched out over millions of years, has produced, in that wonderful bird, the albatross, the perfect flying machine. The future high-speed flyer, then, will possess the same tapering, rounded body and the widespread wings of narrow width which characterize the swiftest of the birds. Langley, in his classic researches, showed that it was the leading portion of a plane which was the most efficient, and this for the reason that it was continually moving on to fresh bodies of undisturbed air. He showed that as the after portion and one which, in the event of the inevitable breakages, incidental to experimental work, could be cheaply and quickly repaired. Its place will be taken by some one of the many remarkable alloys of steel which are now available-metals of enormous strength and tough coupled with careful designing by the skilled engineer, will make it possible to produce an airplane of much greater strength, that will weigh no more than the present machine, and will present far less resistance. The principal resistances encountered by an airplane when in flight are those due to the lift and the head surface. The resistance due to the lift is fairly constant; for as the speed increases the angle of incidence decreases, and there is always an adjustment betw the two which provides sufficient des sufficient to 1,000 pounds, as the case may be. The head resistance, however, increases approximately as the square of the speed; and if it is 100 pounds, say, at 40 miles per hour, it will rise to 400 pounds at 80 miles per hour. Hence the great importance, in a racing machine, of reducing the head surface to the least possible limit consistent with structural requirements.

It is the consideration of head resistance which has ness in proportion to their weight. The use of these,

tion. Unquestionably, the higher speeds which have been attained by the monoplane are due largely to the fact that its trussing is simpler, and the head surface, particularly of the wire stays, is relatively much less. Now a word as to the resistance offered by a mass his whirling-table experiments that the resistance of a wire is much greater than that which would be due to its projected area. As the speed increased, the resistance would rise rather quickly until, at a certain critical point, at which the wire would sing with a peculiar note, there was a sudden and very large jump in the resistance. This is explained by the fact that the rate of vibration of the wire under the rush of air is so great that it practically presents a solid surface, whose width is equal to the amplitude of vibration. whose width is equal to the amplitude of vibration. the air which is seemingly out of all proportion to its actual surface.

It follows, then, that even the simple king-pin trussing of the Blériot and Antoinette types must go if we are to achieve the high speeds which are predicted for the future racing machine. Now this will be possible only if some high-grade sheet metal is substituted for the canvas of the wing surface, and the necessary transverse bending strength is secured by means of platesteel members enclosed within the wing surfaces and strongly riveted to the structure of the main body of the machine.

The form of wing shown in our drawings will afford a sufficiently strong construction in metal. The wings should widen considerably as they approach the body; for this would provide increasing space between the upper and under surfaces, and allow the depth of the channels to be increased proportionately to the bending stresses. These channels would be carried into the main body and riveted to transverse diaphragms, which should be so cut that the metal of the diaphragm would extend unbroken for some distance into the wings. We are convinced that by careful designing the selection of the highest grades of steel, and by first-class workmanship, it will be possible to provide wings of ample strength without exceeding the limit of weight imposed by airplane requirements. Buckling in the fore and aft direction will be provided against by rolling the metal of the wing surfaces with shallow corrugations, as shown in the drawings. The main body of the airplane (Continued on page 168) 
Helmets and Body Armor in Modern Warfare

$A^{\text {MONG the many in- }}$ A stances of a return to long-abandoned practice which were seen in the great war, was the unirersal adoption of the steel helme and the tentative use of body armor. A work re markable for its wealth of information has recently information has recently been written by Bashford Dean, Ph.D., Curator of Armor, Metropolitan $\mathrm{Mu}$ seum of Art, Major of Ordnance, in charge of Armo Unit, during the war. This book of 325 pages describes the various forms of armor

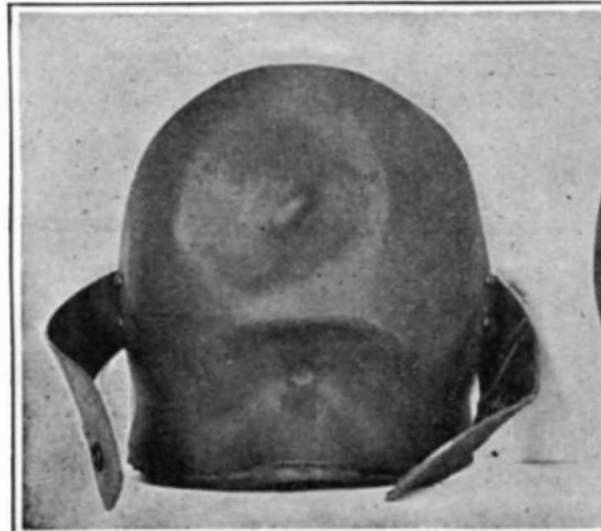

Experimental chin and face guard, front and rear views. Cushioned with sponge rubber
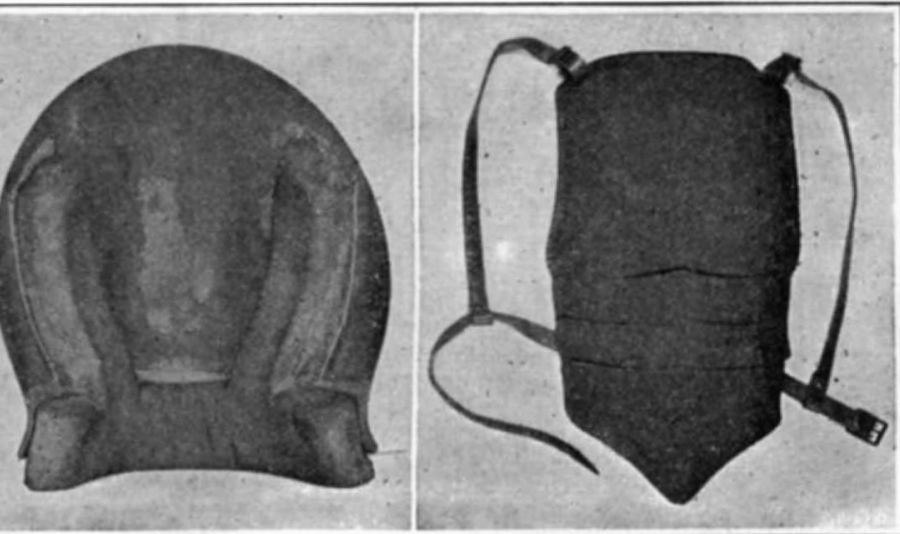

American laminated back plate of man ganese steel. Stops 1000 f.s. bullet designed and used for the American forces, and also discusses most entertainingly the helmets, body armor, et cetera, used by the principal nations engaged in the war. The work is most elaborately illustrated with line drawings and half-tones, and forms necessarily a most comprehensive, up-to-date work on this subject

In the years preceding the war, those of us who passed through the fine hall containing the Riggs Collection of armor at the Metropolitan Museum, regarded it as having an interest purely historical and artistic. Today we look upon those ancient and mediaeval forms with a new appreciation of their value. That armor could have been introduced during the late war and made effective, without loading down the soldier with an impossible burden, is due to the remarkable strides which have been made in the production of high-grade at loy steels of rreat resisting power in proother armor of the mediaeval times would not be effectual in stopping modern highvelocity bullets and shrapnel, but the manganese and other steels employed give to the modern soldier an immunity comparable to that enjoyed by the mediaeval armored knight against battle axe, sword and the swift-flying arrows of the Saxon bowmen.

We have selected a few illustrations from this volume which are characteristic of the several hundreds with which it is richly illustrated. Among these is a type of face guard, a device to accompany a helmet of the British type. This is an

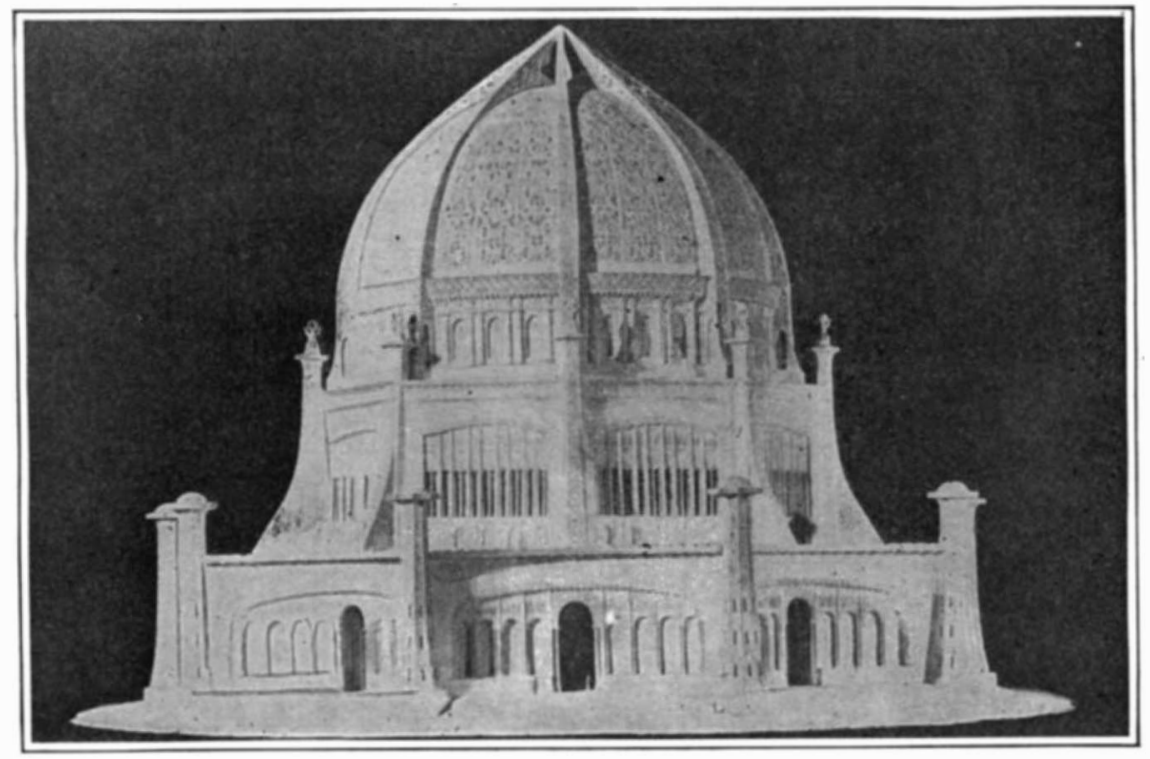

An exotic Bahai Temple for the metropolis of the East and of the West proved type of body defense, the British Government through its Munitions Inventions Board, manufacture the corselet which we illustrate. It weighs nine and one-half pounds and is formed of three elementsbreast plate, a back plate, and what is called a "spor ran" piece. These are covered with khaki drill and are slightly padded. It will resist the ball of th automatic pistol, and also shrapnel and grenade. It New York! This is an astounding proposition in itself, without considering for the moment the archiwell tell the name of this new cult now as later-it is the "Bahai Movement," which, according to its devotees, is to weld together all the religions of the world in a common religious unity. The idea is common enough, and has been shakin the universe since the "Oxford" or "Tractarian" movement in the middle of the last century. It is the desire to gain last century. It is the desire to gain
unity without undue concession which animates all real inquirers.

The Bahai movement assumes that there are nine of the great religions and that in a temple there should be nine sides with doors over which are inscribed a welcome in the language of the race to which the portal belongs. Within we are not to see nine pulpits with nine kinds of priests, rabbis, or exhorters in nine kinds of vestments or without them. The paraphernalia of religion is left ont in the daylight, and in the dim religious light we have worship, music, and, above all, beauty. The effect produced on the visitor would be something akin to that wonderful Masonic Scottish Rite Hall in Washington where even the most hardened atheist and sinner would be soft ened by the combination of music and dim religious atmosphere. There is no other creed than the brotherhoos of man and no other organization than a body of adaptation of the face guard of the fifteenth century. It encloses the face, rests on the chest and is held in position, not too tightly, by leather bands provided position, not too tightly, by leather band with snap fasteners. To absorb the shock of impact, the rubber. This guard stopped the automatic revolver bullet at ten feet. A number were sent to the training camps
and tried out and although the soldiers complained that it was a bit "stuffy." there can be no doubt of its value. That it is practical seems clear from the fact that the same form was in general use in Europe from 1450 to 1550.

We also reproduce the photograph of an experimental American body armor which consists of five pieces. The upper and larger portion covers the chest and stomach; to this are riveted two sections which protect the abdomen; below this, attached by leather straps and buckles, are two pieces of armor which afford protection to the upper part of the thighs. This armor is made of Baker's nickel-manganese alloy, and in the tests, at a distance of 200 yards, it served to stop a rifle ball served to stop a rifle ball fired with an initial velocity
of 2,800 feet per second. of 2,800 feet per second.
With this may be compared the British body armor brought out in 1917-18. In its effort to furnish an im-

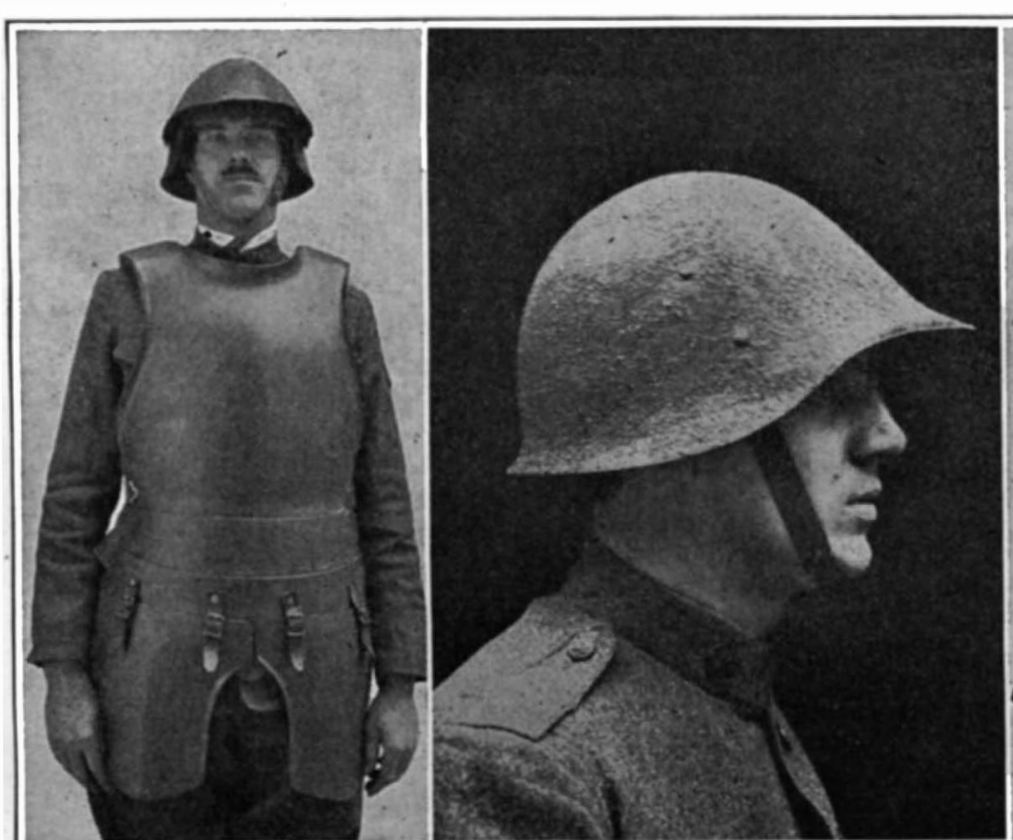

Experimental American body American helmet No. 2. Improvement armor. Stops rifle bullet at 200 yards will stop a bullet traveling at a rate of 1,280 feet per field's manganese steel of eighteen gage. This model was issued in pretty large quantities.

Between these samples of American and British armor we show an American model helmet which, the war had continued, would probably have super(Continued on page 168)

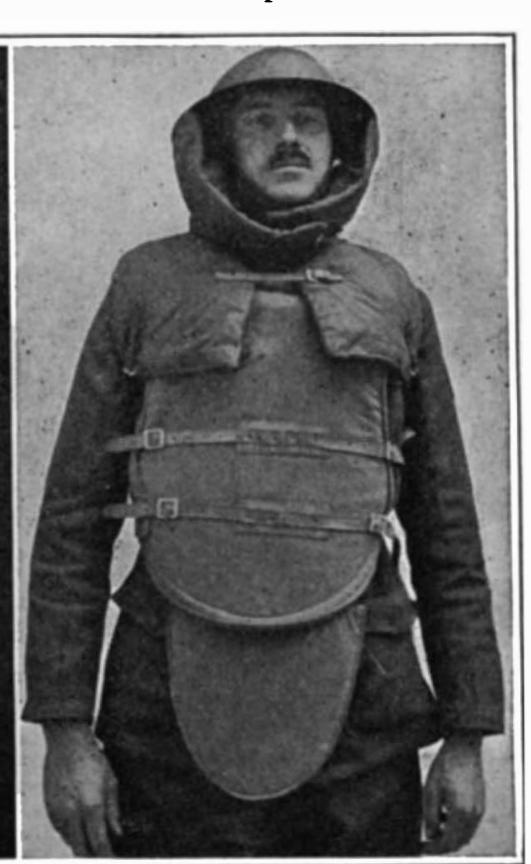

British body armor of 1917-18. per second velocity Stops rifle bullet at 1280 feet
The plans of the architect, Louis Bourgeois, diffe somewhat in his earlier and later models, but our illustration suggests a compromise design which for real beauty is almost without a peer.

The architect has wrought into his decorations such The architect has wrought into his decorations such symbols as the cross, the swastika, the five, six and figures has been eschewe and purely mathematica lines have been substituted. inspiration from the stud of astronomy, for the overlapping curves which the planets trace in their different planes are very beautiful as they circle around in the heavens. The dome is the essential feature and somewhat suggests the socalled "Dome of the Rock" in Jerusalem, wrongly called the "Mosque of Omar." The external ribs are most pronounced meeting in Gothic point, suggesting hands clasped in prayer above the head.

The first story is Roman in its window arches, while the second is more Greek, and the next story suggests Chinese influence. In fact, it is a remarkable architectural blending. The building will cost several millions, but the result will be worth it.-By A. A. Hopkins. The architect has derived his 


\section{In "the good old days"- when meat was "cheap"}

Years ago people were buying steaks and chops "cheap" and other meats in proportion.

It is true that meat prices are higher today - and so is the price of live stock.

But--

If present-day methods had been in use fifty years ago, meat would have cost our fathers and mothers and uncles and aunts even less than it did!

Many parts of the animal were actually thrown away; the business was done in small unsanitary plants.

As a matter of fact, meat was not cheap in the early days as compared with the price of live stock. See what U. S. Census figures show:

In 1870 it took nearly 19 per cent of the value of meat products to cover the packer's exanimals into meat; the latest census shows that with modern methods it took less than meat products to perform this same service.

This smaller relative "spread" between live stock and meat prices is due to development of large scale operations and elimination of waste. It means that meats are cheaper today than they used to be, compared with the cost of raising live stock.

Out of all receipts from the sale of animal products last year, Swift \& Company paid out over 85 per cent for the live animals. The other 15 per cent covered all plant, shipping, and selling expenses - and also the profit, which averaged only a fraction of a cent per pound on all products sold. penses and profits for turning 13 per cent of the value of

\section{Swift \& Company, U. S. A. Founded 1868}

$A$ nation-wide organization owned by more than 35,000 shareholders
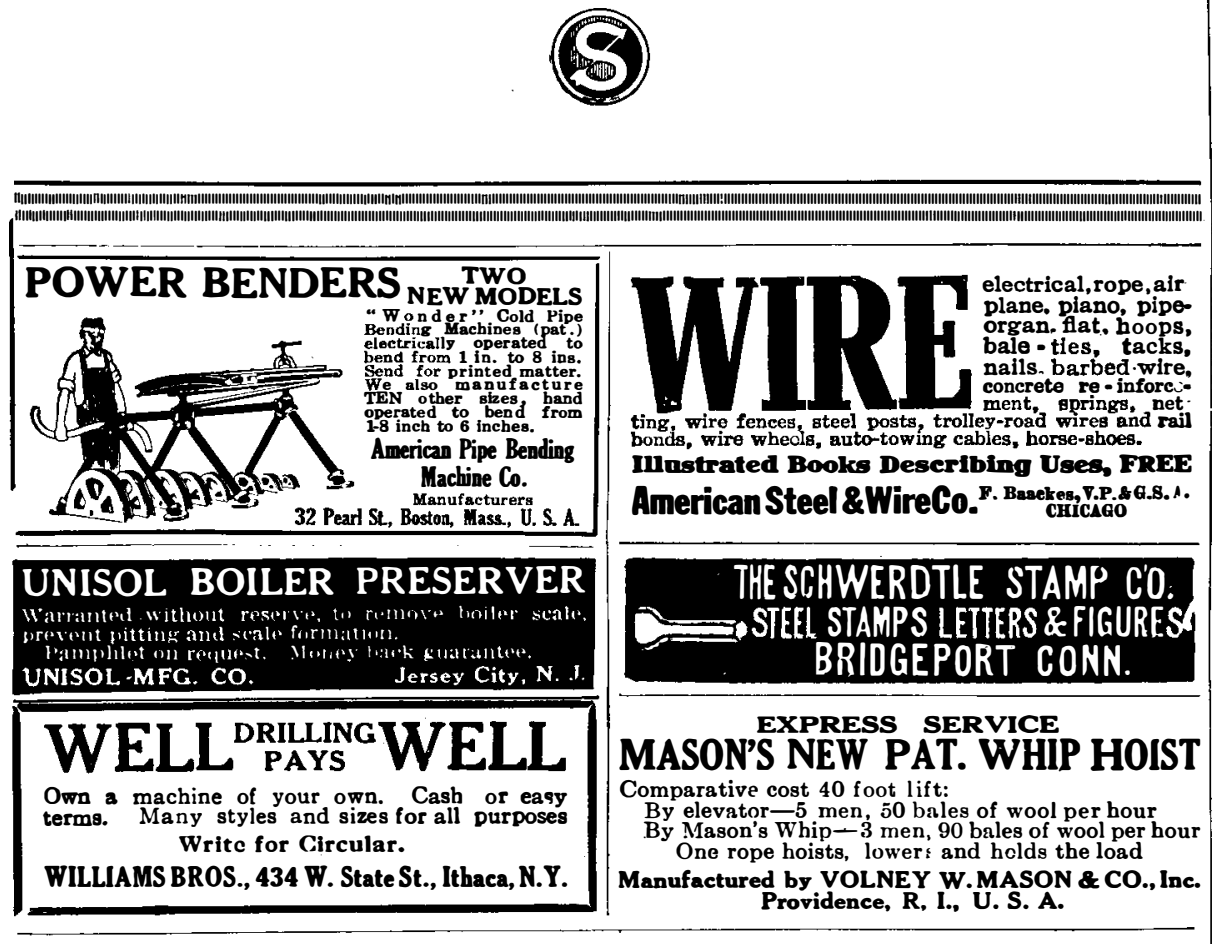

Now Ready! $A$ New Book on a New Subject

BEHIND THE MOTION-PICTURE SCREEN By Austin C. Lescarbour

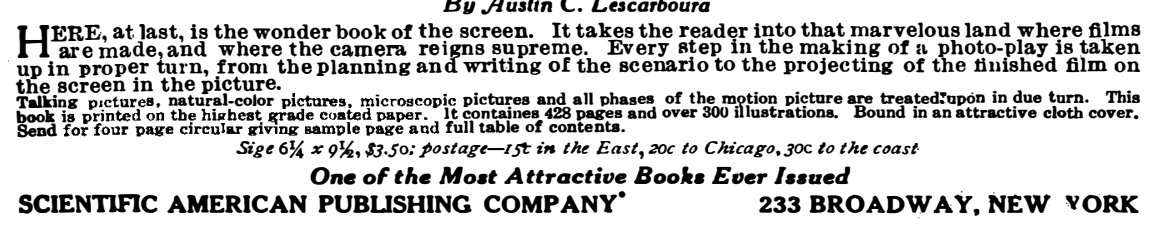

"orershot" and the "swing-around" |these
stacker. Each of these has long wooden iron. on these teeth. When the push rake is operated properly, there is no necessity for hand work, except that occasionally hay with a fork when several push rakes are used. Two horses, or a tractor, are used to elevate the hay to the proper height to be dropped on the stack.

The second type, stackers that do not receive hay directly from push rakes, but handle it by means of horse forks or slings, are usually home-made stacking outfits, and there are a number of these. The cable stacker is one of the simplest and most generally used, and consists of an A-shaped frame higher than the hav stack to be built, to which is fastened steel cable on which the carrier travels The materials for such a stacker can be obtained on the farm or from any hard ware store. The single-pole or derrick stacker is used to a considerable extent, and it consists of a single pole long enough to make a stack of the desired height, to which is fastened a shorter pole, or boom, at right angles. Three pulleys, about 100 feet of rope, and a horse fork complete the outfit. Where a number of stacks are to be built, it is customary to mount the pole on wheels or on runners, which can be easily moved. The pole is supported by three or four guy ropes or wires.

In what is known as the "Black Belt" in Georgia, Alabama and Mississippi, there has been developed a successful type of truck for curing hay. In this section the principal kinds of hay grown for market are alfalfa, Johnson grass, and alfalfa and Johnson grass mixed. The hay-making season covers a period of several months, and from three to five cuttings are obtained per year. The great drawback in producing hay, however, is the difficulty in curing the hay during unfavorable weather. The hay-curing truck was designed to enable the grower to cure hay during rainy or cloudy spells of weather when all ordinary methods of curing in the field failed.

The curing truck is a device which supports hay during the curing process, protecting it from rain and from moisture in the ground. It requires no more man labor or horse labor for loading, unloading or hauling than do the more familiar methods of curing.

The truck is quite similar to the ordinary hayrake. It is $\mathbf{1 2}$ feet long and $\mathbf{T}$ feet wide and will hold from 1,500 to 2,000 pounds of cured hay, depending on how much the hay is cured when put on the truck. The back is supported by two 16 to 20 -inch steel or iron wheels running on an axle placed about 4 feet from the rear end of an A-shaped frame. When a loaded truck is not in motion, as when left in the field for the hay to cure or while it is waiting to be baled, the front end is supported by a 6 by 8-inch wooden block or "trigger" of sufficient length to hold the truck level. This trigger is fastened between the two main frame timbers ened between the two main frame timbers
by a heavy bolt, enough play being left so that it swings easily by its own weight. When the trigger is not in use the free end, pointing to the rear, drags lightly on the ground. The trucks are moved by means of a two-horse team and by reason of their being moved from place to place, the hay can be either left out in the open on bright days or placed under shelter in times of storm. A canvas covering will protect the hay from the top, and the hay being off the ground, will prevent being spoiled by excessive ground moisture.

\section{The Racing Airplane of the Future}

\section{(Continued from page 158)}

will be built also of thin sheet metal, and will be generally elliptical in cross section; two very light trusses, one horizontal, the other vertical, extending from the operator to near the tail. The chords of
To provide for the heavy loads and resses that are concentrated at the wings and motor, the T-irons of the trusses will be increased in depth and run entirely around the forward end of the body, forming, at their intersection in the nose, a strong construction for carrying the motor. Additional strength will be provided by transverse diaphragms. It is understood, of course, that all of this metal work will be specially rolled in extremely light sections, and that the material will be some alloy, such as vanadium steel, which in experimental specimens, as noted on our editiorial page, has shown elastic limits running up to over 200,000 pounds to the square inch. The motor of from 75 to 150 horse-power, ac cording to the size of the airplane, will probably be of the revolving type; the Gnome motor having shown itself to be the ideal airplane drive.

Turning to nature for guidance again, we find that the fast-flying birds fold their legs snugly beneath them when in flight. The racing airplane must do the same. We show a suggested arrangement for a folding chassis, hinged just below the body, and provided with a yoke which leads from the axle up to the crosshead of a piston rod, which, with the guides and cylinder, is carried by the T-iron that forms the bottom member of the vertical truss. The cylinder is provided with a two-way valve and connections by which compressed air can be introduced to the forward or after end of the cylincler. When the chassis is down and in operation, the compressed air acts as a cushion to provide a certain amount of fore and aft movement to the wheels. As soon as the machine rises, a throw of the valve introduces compressed air at the forward end of the cylinder, and the chassis is drawn up snugly against the body. A small tank of compressed air, which supplies the folding mechanism, also supplies a small cylinder of similar construction placed transversely to the car, which operates the movable wing tips. The twoway valve of this cylinder is controlled by a small gyroscope, which may be thrown out of gear when the airman wishes to make a turn, or perform other evolutions.

In answer to the question as to what speed may be expected from a machine of this general design, we think it will be agreed that, in view of its sweetness of form, the complete absence of wires struts and other energy-consuming surfaces, and the fact that because of the smoothness of the steel surface, skin friction will be reduced to a minimum-it is conservative to expect from such a ma-
chine, after it has been developed by experimental work, speeds of from 100 to 125 miles an hour.

It would be interesting to see what $\mathrm{Mr}$. Her reshoff could accomplish, if he applied to the steel airplane the same constructive genius which enabled him to produce such fine results with steel racing yachts.

Helmets and Body Armor in Modern Warfare

\section{(Continued frcm page 159)}

seded the "porridge bowl" English helmet It was made of manganese steel, and it has the advantage over the old type that it protects the back and sides of the head better than the earlier model.

We show also an American experiment al back plate which is laminated. It is made up of a large upper plate, two in termediate pieces, and a lower-most plate or garde reins. These elements are riv eted together and are made interflexible by the use of slotted grooves in which the rivets can travel, as in the old-fashione "alemayne rivets." The back plate is to suit wearers of many sizes, an is cushioned with sponge rubber that serves to protect the wearer against in juries from indentation of the metal. I will stop a bullet traveling at 1,000 feet per second. 